\title{
Equalização da disputa ou reprodução de desigualdades? Uso do Facebook por candidatas à Câmara Federal por São Paulo em 2018
}

\author{
Catarina Helena Cortada Barbieri ${ }^{1}$ (D) \\ Luciana de Oliveira Ramos ${ }^{2}$ \\ Ivan Osmo Mardegan ${ }^{3}$ \\ Juliana Fabbron Marin Marin ${ }^{4}$ \\ Lais Menegon Youssef ${ }^{5}$ (iD)
}

\begin{abstract}
Neste artigo, analisamos o uso de ferramentas do Facebook em campanhas eleitorais de candidatas ao cargo de deputado federal por São Paulo com o objetivo de avaliar se esse uso mitiga ou reproduz desigualdades socioeconômicas estruturais que elas vivenciam em sociedade. Acompanhamos o uso do Facebook durante a campanha eleitoral de 2018 visando entender especificamente se e como essa rede social foi utilizada por essas candidatas. A partir de uma base de dados com mais de 55 mil postagens de 465 candidatas, incorporamos um olhar interseccional sobre as múltiplas identidades dessas mulheres e correlacionamos seus marcadores sociais (estrato sócio-ocupacional, grau de instrução, idade e raça/cor) com o uso do Facebook durante a campanha eleitoral. Os resultados das análises quantitativas apontam que, em vez de mitigar as desigualdades socioeconômicas preexistentes, essa rede social acabou por reproduzi-las ao longo da campanha.
\end{abstract}

Palavras-chave: campanhas eleitorais; Facebook; internet; mulheres na política; desigualdades

\footnotetext{
1 Fundação Getulio Vargas, Escola de Direito de São Paulo, Núcleo de Gênero e Direito. São Paulo (SP), Brasil. E-mail: <catarina.barbieri@fgv.br>.

2 Fundação Getulio Vargas, Escola de Direito de São Paulo, Núcleo de Gênero e Direito. São Paulo (SP), Brasil. E-mail: <luciana.ramos@fgv.br>.

3 Fundação Getulio Vargas, Escola de Administração de Empresas (Eaesp) e Centro de Estudos em Política e Economia do Setor Público (Cepesp-FGV). São Paulo (SP), Brasil. E-mail: <ivan.osmo@gmail.com>.

${ }^{4}$ Fundação Getulio Vargas, Escola de Administração de Empresas de São Paulo (Eaesp) e Escola de Direito de São Paulo. São Paulo (SP), Brasil. E-mail: <julianafabbron@gmail.com>.

5 Fundação Getulio Vargas, Escola de Direito de São Paulo. São Paulo (SP), Brasil. E-mail: <laisyoussef@gmail.com>.
} 


\section{Introdução ${ }^{6}$}

Neste artigo, buscamos responder se, no contexto da disputa eleitoral de candidatas ao cargo de deputado federal por São Paulo em 2018, o uso do Facebook contribuiu para a reprodução de desigualdades socioeconômicas enfrentadas pelas mulheres na sociedade ou atuou de modo a mitigá-las. A intenção é entender se, durante o período eleitoral, um recurso não tradicional de campanha - as redes sociais -, que, a princípio, não depende de lideranças e estruturas partidárias para ser utilizado, é capaz de reduzir as desigualdades relativas a raça, grau de instrução, idade e estrato sócioocupacional preexistentes no ambiente offline entre as candidatas.

O pano de fundo deste artigo está relacionado à desigualdade entre homens e mulheres no acesso a essa política e na participação nesse espaço. Atualmente, as mulheres constituem apenas $25 \%$ dos parlamentares no mundo, segundo dados da União Interparlamentar 7 . Ou seja, a maioria dos parlamentos continua dominada por homens, e alguns não possuem sequer uma mulher. Isso significa que as mulheres, embora representem mais de $51 \%$ do eleitorado ao redor do globo, ainda estão excluídas da participação igualitária nos espaços de tomada de decisão sobre leis e políticas públicas.

Todavia, para avançar no debate acerca da desigualdade entre homens e mulheres no acesso aos cargos eletivos, é necessário ir além do binarismo de gênero e buscar captar as barreiras que as múltiplas fontes da identidade das mulheres impõem ao acesso à disputa eleitoral e às habilidades de explorar as potencialidades das ferramentas de campanha, em especial as redes sociais.

O foco do artigo é o acesso à rede social Facebook e seu uso por essas candidatas, mas, em conjunto com o marcador de gênero, nossas análises incluem as variáveis raça/cor ${ }^{8}$ (declarar-se branca ou não), grau de instrução (ter ensino superior completo ou não), estrato sócio-ocupacional (pertencer a estratos mais altos ou não) e idade. Assim, é

\footnotetext{
${ }^{6}$ Este artigo é fruto de achados da pesquisa "Democracia e representação nas eleições de 2018: campanhas eleitorais, financiamento e diversidade de gênero", desenvolvida no âmbito da Escola de Direito de São Paulo da Fundação Getulio Vargas (FGV Direito SP), em parceria com o Centro de Política e Economia do Setor Público da FGV (Cepesp). Coordenada pelas professoras Catarina Barbieri e Luciana Ramos, a pesquisa foi agraciada com o financiamento do Fundo de Pesquisa Aplicada da FGV, o que viabilizou a execução desse projeto coletivo. Integraram a equipe de pesquisa Aline Herscovici, Fernanda Moraes, Hannah Maruci Aflalo, Ivan Mardegan, Juliana Fabbron Marin Marin, Laís Youssef e Vanilda Chaves. Agradecemos o apoio de Clara Batista, Danilo Sousa, Fernanda Cimetta, Helena Funari, Isla Andrade, Lívia Buzolin e Rafaella Monesi, que auxiliaram na coleta de dados do Facebook durante a campanha eleitoral de 2018. Agradecemos às (aos) pareceristas anônimas(os) pelos comentários que contribuíram enormemente para a versão final do texto. Versões preliminares deste artigo foram apresentadas em seminários de pesquisa no InternetLab (São Paulo, Brasil) e no Institute of the Americas (University College London, Reino Unido). Agradecemos particularmente as sugestões e críticas de Mariana Valente e Malu Gatto.

7 Os dados mencionados estão disponíveis no site da União Interparlamentar, mais especificamente no link <https://data.ipu.org/women-averages?month=6\&year=2020\&op=Show +averages\&form_build_id=form4t-x0rNb3uPXo4BC7b1hzGLg7X-QYSZGKzLX4Iq4kUg\&form_id=ipu_women_averages_filter_form>. Último acesso: 8 jul. 2020.

8 No presente artigo, utilizamos a nomenclatura adotada pelo TSE, portanto, raça/cor, visto que todas as nossas análises são provenientes de dados disponibilizados pelo Tribunal.
} 
a partir de um olhar interseccional que nos debruçamos sobre a questão para entender se há e quais seriam as diferenças entre as candidatas no acesso ao Facebook e no seu uso em suas campanhas.

As eleições gerais de 2018 trouxeram diversas novidades, entre elas, a possibilidade de uso de redes sociais como instrumento de campanha eleitoral, tendo sido, por exemplo, regulamentada a possibilidade de "impulsionamento" de conteúdos ${ }^{9}$. Com base na suposição de que as redes sociais não requerem investimento inicial para a propagação de informações, posto que são, a princípio, gratuitas, e, sobretudo, de que não dependem de decisões das executivas dos partidos (como é o caso da distribuição de recursos dos fundos eleitorais e de tempo na TV e no rádio), poderíamos assumir provisoriamente que elas se tornaram um importante instrumento de campanha, principalmente para candidaturas de mulheres que receberam pouco ou nenhum apoio partidário, o que, por si só, justificaria a necessidade de uma análise mais detida de como se deu esse uso. Desse modo, candidaturas com menos recursos financeiros, apoios simbólicos, menos estrutura e/ou menor experiência de campanha poderiam, em tese, disputar novos eleitores, aos quais não teriam acesso via outros meios de comunicação, e aumentar ou potencializar seu contato com possíveis eleitores já existentes.

Importante salientar que o foco deste artigo não é apontar qualquer predição quanto ao resultado da eleição, ou seja, o objetivo não é fazer qualquer afirmação sobre se o uso dessas ferramentas na rede social teve influência no sucesso nas urnas. $O$ intuito é compreender se as desigualdades socioeconômicas presentes na sociedade brasileira e experienciadas por mulheres marcadas por múltiplas identidades e, assim, com diferentes estratos sócio-ocupacionais, graus de instrução, idade e raça/cor, se reproduzem no uso do Facebook durante uma campanha eleitoral. A hipótese explorada é a de que o uso do ambiente virtual poderia nivelar as condições de campanha entre as candidatas, que, de antemão, são diferentes entre si em virtude das desigualdades estruturais preexistentes ao processo de eleição.

A literatura vem apontando que as características das pessoas importam quando falamos sobre o uso da internet. Não apenas no sentido do acesso em si, ou seja, ter equipamento e acesso à internet ou não, mas também sobre as habilidades que as pessoas precisam ter para melhor usufruir dos instrumentos oferecidos pelos ambientes virtuais de forma a atender a seus interesses e maximizar os benefícios (Hargittai, 2002; Ribeiro, Borba e Hansen, 2019). Essas habilidades podem ser afetadas pelo perfil socioeconômico do usuário e por outros fatores, como idade, raça/cor, escolaridade e recursos financeiros

\footnotetext{
9 Diferentemente das eleições anteriores, 2018 foi a primeira vez que se permitiu a realização de impulsionamento de postagens no Facebook, conforme disposto no art. 57-C, introduzido na Lei Federal no 9.504, de 1997, pela Lei no 13.488 , de 2017, que dispõe: "É vedada a veiculação de qualquer tipo de propaganda eleitoral paga na Internet, excetuado o impulsionamento de conteúdo, desde que identificado de forma inequívoca como tal e contratado exclusivamente por partidos, coligações e candidatos e seus representantes". Disponível em: <http://www.tse.jus.br/legislacao/codigo-eleitoral/lei-das-eleicoes/lei-daseleicoes-lei-nb0-9.504-de-30-de-setembro-de-1997>. Último acesso em: 21 dez. 2018.
} 
(Ribeiro, Borba e Hansen, 2019; Gulati e Williams, 2013; Robinson et al., 2015; Herrnson, Stokes-Brown e Hindman, 2007; Marques, Aquino e Miola, 2014). Em resumo, esses estudos apontam que pessoas mais jovens, brancas, com nível educacional mais elevado e com maior acesso a recursos financeiros usariam a internet, incluindo as redes sociais, de forma quantitativa e qualitativamente superior.

No contexto brasileiro, os ambientes offline são conhecidos pela elevada desigualdade social e pelas diferenças de oportunidades, principalmente quando abordamos aspectos relativos a raça/cor e renda, prevalecendo os privilégios de pessoas brancas e de classes sociais mais abastadas. No contexto eleitoral offline, a distribuição de recursos eleitorais também é marcada por forte desigualdade (Campos e Machado, 2015; Sacchet e Speck, 2012a, 2012b). Essas desigualdades podem ser reproduzidas ou até acentuadas em ambientes online (Hargittai e Hsieh, 2013). Nesse sentido, o acesso a recursos financeiros pode se mostrar um importante preditor da adoção do Facebook nas campanhas eleitorais (Gulati e Williams, 2013). A hipótese aventada por esses estudos é a de que grupos que se encontram em desvantagem offline provavelmente usam a internet de forma menos intensa do que os mais privilegiados.

Para analisar se as desigualdades offline foram reproduzidas em ambiente online no contexto da disputa eleitoral brasileira - mais especificamente na disputa por diferentes perfis de mulheres ao cargo de deputado federal -, monitoramos as Páginas e os Perfis do Facebook das 465 candidatas que concorreram a esse cargo por São Paulo nas eleições de 2018. Durante todo o período de campanha, foram coletadas as seguintes informações ligadas ao uso do Facebook: acesso à ferramenta, sua manutenção durante o período eleitoral (uso contínuo), o número total de publicações realizadas pelas candidatas, o número de publicações concernentes à campanha da própria candidata em relação ao total de postagens e, por fim, a existência de impulsionamento de publicações.

Em seguida, cruzamos esses dados com quatro variáveis relativas ao perfil socioeconômico das candidatas - estrato sócio-ocupacional (pertencer a estratos mais altos ou não), grau de instrução (ter ensino superior completo ou não), raça/cor (declararse branca ou não) e idade -, a fim de examinar se o uso do Facebook foi realizado de forma equivalente por mulheres com características socioeconômicas diversas, o que indicaria uma mitigação das desigualdades estruturais da sociedade. Em contrapartida, se encontrarmos padrões variados de utilização entre grupos de candidatas diferentes que apontem para a melhor utilização da ferramenta por pessoas de estratos sócioocupacionais mais elevados, com grau de instrução mais alto, brancas e mais jovens, poderemos concluir que houve a reprodução das desigualdades no uso do Facebook.

Para responder à pergunta da pesquisa, o artigo está estruturado em quatro partes, além desta introdução, sendo que as duas primeiras, "Gênero e interseccionalidade: impacto nas análises sobre a inserção de mulheres na política institucional" e "Desigualdades digitais em campanha eleitorais: do acesso às habilidades 
de manejo da internet", têm por objetivo apresentar os referenciais teóricos e metodológicos mais amplos que fornecem as lentes analíticas para a pesquisa. A primeira parte contempla os estudos de gênero e interseccionalidade e seus desdobramentos nas análises sobre a inserção de mulheres na política institucional, particularmente em campanhas eleitorais, objeto deste trabalho. Na segunda parte, apresentamos os resultados de estudos sobre desigualdades digitais no acesso à internet e às redes sociais e no seu uso. Em seguida, em "Nota metodológica", apresentamos a metodologia de análise quantitativa para, na quarta parte, explicitar os resultados dela decorrentes. Finalizamos com as "Considerações finais".

\section{Gênero e interseccionalidade: impacto nas análises sobre a inserção de mulheres na política institucional}

Nas últimas décadas, a desigualdade na participação de homens e mulheres na política institucional tem recebido especial atenção na agenda de direitos. Atualmente, os parlamentos nacionais são compostos majoritariamente por homens, com exceção de apenas três países ${ }^{10}$. Isso significa que as mulheres estão sub-representadas nesses espaços de poder e tomada de decisão política sobre os principais rumos de uma nação. No Brasil, esse cenário de sub-representação é bastante acentuado e coloca o país entre os piores do mundo, uma vez que ele está na $141^{a}$ posição do ranking da União Interparlamentar, com apenas $14,6 \%$ de mulheres representadas na Câmara dos Deputados.

A desigualdade de gênero na política institucional no Brasil e na maioria dos países do globo motivou a realização de diversos estudos para entender as razões da baixa presença de mulheres. O debate acadêmico nacional e internacional tem se debruçado sobre todas as etapas do processo eleitoral e da participação política para entender essas diferenças de gênero no acesso aos cargos eletivos.

As causas para a sub-representação de mulheres apontadas pela literatura englobam explicações de cunho institucional, que vão desde a análise das interações entre as regras eleitorais e o sistema político (Norris, 2013; Kittilson e Schwindt-Bayer, 2012; Htun e Jones, 2002; Matland, 1998; Rule e Zimermman, 1994) até o estudo das limitações das leis de cotas enquanto política afirmativa de inserção de mais mulheres na política (Krook e Norris, 2014; Krook, 2004, 2009; Araújo, 2001; Htun, 2001), passando pela análise do papel dos partidos políticos na seleção e recrutamento de candidatas viáveis ou com chances de se eleger (Araújo, 2005; Shvedova, 2005; Norris e Lovenduski, 1995).

\footnotetext{
10 São eles: Ruanda (primeiro lugar no ranking, com 61,3\% de mulheres entre os parlamentares), Cuba (com 53,2\%) e Emirados Árabes Unidos (com 50\%). O ranking elaborado pela União Interparlamentar relativo a junho de 2020 está disponível em: <https://data.ipu.org/women-ranking?month=6\&year=2020>. Último acesso em: 11 jul. 2020.
} 
Há também estudos que explicam a sub-representação de mulheres na política formal devido ao processo de socialização voltado para a esfera privada a que estão submetidas, o que limita seu acesso a determinados tipos de redes sociais e políticas que poderiam ser ativados na arrecadação de recursos (Ballington, 2003; Sacchet, 2009). Ante a constatação de que os homens tendem a se organizar em grupos voltados à esfera pública e as mulheres participam mais de grupos que lidam com questões práticas do cotidiano familiar e comunitário, Sacchet (2009) ressalta que "as desigualdades sociais de gênero, classe, etnia etc. - estão relacionadas à distribuição desigual de recursos e de acesso a diferentes redes que favorecem a troca de informação e criam oportunidades para o desenvolvimento político e social desses grupos" (p. 327).

Há, ainda, estudos que demonstram que a destinação de menor quantidade de recursos às campanhas de mulheres em comparação às campanhas de homens é um obstáculo importante para o sucesso eleitoral de candidatas (Speck e Mancuso, 2014; Sacchet e Speck, 2012a, 2012b). Ao compararem a arrecadação de campanha de mulheres e homens candidatos aos cargos de deputados federal e estadual no pleito de 2006, Sacchet e Speck (2012b) concluíram que as mulheres têm arrecadações de campanha significativamente menores que as dos homens. E mesmo que controlados pelo fator reeleição, os dados mostram que a diferença diminui, mas persiste. Uma arrecadação menor para as campanhas de mulheres faz com que as suas candidaturas não alcancem o mesmo potencial que as masculinas, prejudicando as suas chances de se eleger.

Tais estudos mostram que as mulheres, de forma geral, têm enfrentado diversos obstáculos de acesso à participação na política institucional. Como se viu, elas têm maior dificuldade de acesso a recursos tradicionais que são controlados pelas instâncias internas dos partidos: elas recebem menos recursos financeiros que os candidatos homens e têm menos acesso às redes de contatos que possibilitam maior arrecadação de verbas de campanha. Esse estado de coisas reduz as chances de ganharem mais visibilidade e se tornarem mais competitivas, com reais possibilidades de conquistar uma cadeira no parlamento.

Acontece que esses obstáculos de acesso a recursos partidários tradicionais não recaem igualmente sobre todas as mulheres. Mulheres brancas parecem ter mais condições de superá-los e acessar a política formal, tendo em vista que, das 77 mulheres eleitas à Câmara Federal em 2018, 82\% são brancas, 17\% são negras e 1\% é indígena. Nas eleições de 2014, das 51 mulheres eleitas, $80 \%$ eram brancas e $20 \%$, negras ${ }^{11}$.

Assim, para aprofundar a análise da desigualdade entre homens e mulheres no acesso à política formal, é preciso levar em conta as diversas formas de opressão que recaem sobre as mulheres, incluindo as decorrentes dos marcadores de raça/cor, classe

\footnotetext{
11 De acordo com levantamento feito pelo portal Gênero e Número a partir de dados do TSE, disponíveis no link: <http://www.generonumero.media/camara-dos-deputados-tera-mais-mulheres-brancas-negras-eindigena-e-menos-homens-brancos-em-2019>. Último acesso: 12 jul. 2020.
} 
social, idade, entre outros. Essa preocupação em compreender as múltiplas e imbricadas formas de opressão está ligada à noção de interseccionalidade.

O uso desse termo ficou notório depois da publicação da análise de Crenshaw (1989) sobre as variadas formas em que gênero e raça se imbricavam na discriminação sofrida por mulheres negras no ambiente de trabalho e na própria tutela jurídica relacionada a essas demandas. A ideia original de Crenshaw - analogia com um cruzamento em uma estrada (intersection) - era que mulheres negras sofriam discriminação de gênero e raça, ao mesmo tempo, no âmbito do trabalho. Tratava-se de uma opressão com múltiplas faces. A via da raça não era independente da via do gênero: a mulher negra vivia esse entrecruzamento na sua experiência, que não se resumia à soma de opressões individualmente consideradas. O direito antidiscriminatório nos Estados Unidos à época, argumentava Crenshaw, falhava em apreciar a intersecção, deixando social e juridicamente desassistidas mulheres negras discriminadas nas relações de trabalho. Ferramenta teórico-analítica pensada por feministas negras, os estudos sobre a interseccionalidade enfatizam o modo como a interação das opressões de gênero e raça impacta a vida de mulheres negras (Akotirene, 2019; Carneiro, 2009, 2011; Hooks, 2015; Gonzales, 1984).

Às categorias raça e gênero foram sendo, posteriormente, agregados outros marcadores de diferença, como classe social, orientação sexual, etnicidade, idade, deficiência (Davis, 2016; Hirata, 2014; Hill Collins, 2019; Gonzales, 1988). A literatura sobre a articulação desses eixos cresceu substancialmente, permitindo o reconhecimento de novas e específicas formas de opressões atuantes sobre as mulheres, sobretudo de grupos socialmente subalternizados, expondo, inclusive, as hierarquias e opressões impostas por mulheres pertencentes a grupos socialmente dominantes sobre outras mulheres. De acordo com Hill Collins e Bilge (2016), a interseccionalidade adiciona camadas de complexidade a vários temas, como desigualdade social, poder, relacionalidade e justiça social. No que diz respeito à desigualdade social e à organização do poder em uma dada sociedade, as autoras sustentam que há divisão social, seja de raça, gênero ou classe, mas existem muitos eixos que trabalham juntos.

Bilge (2009) sintetiza o conceito de interseccionalidade: "teoria transdisciplinar que visa apreender a complexidade das identidades e das desigualdades sociais por intermédio de um enfoque integrado" ( p. 70). Para a autora, o "enfoque interseccional vai além do simples reconhecimento da multiplicidade dos sistemas de opressão que opera a partir dessas categorias e postula sua interação na produção e na reprodução das desigualdades sociais" (p. 70).

No Brasil, a transposição desse instrumento teórico-metodológico para os estudos empíricos sobre o comportamento de mulheres em campanhas eleitorais vem ocorrendo paulatinamente. Estudos sobre gênero, raça, etnicidade, classe social e idade no acesso aos cargos eletivos na política brasileira também vêm crescendo, ainda que a ausência do 
registro de dados sobre raça/cor pelo TSE até 2012 - que atualmente é autodeclarado na ficha das candidatas - em muito tenha dificultado esse avanço. Há estudos pioneiros que trabalharam fatores tradicionais para a sub-representação de mulheres negras e brancas e de homens negros até as eleições gerais de 2010, mas que enfrentaram dificuldades devido à falta de dados relacionados a raça/cor/etnia (Santos, 2010; Meneguello et al., 2012). Há ainda estudos que se concentram nas mulheres negras na política, mas que têm como escopo o modo como os discursos em relação a essas representantes ou candidatas são construídos pela mídia e por formadores de opinião (Carneiro, 2009; Gomes, 2018). Ademais, existe um crescente corpo de pesquisas avaliando as particularidades e os desafios da inserção das mulheres indígenas brasileiras nos processos político-eleitorais estas também marcadas por profundas diferenças entre si (Segato, 2003; Pinto, 2010; Souza e Cemin, 2012; Pacheco, 2017), sem contar alguns importantes estudos que focam homens e mulheres indígenas conjuntamente, como Codato, Lobato e Castro (2017),

Buscando contribuir para o avanço dessas pesquisas sob a lente teóricometodológica da interseccionalidade, este artigo se propõe a analisar este novo aspecto das campanhas eleitorais: o uso de redes sociais. Dentro do grupo de candidatas ao cargo de deputado federal por São Paulo nas eleições de 2018, verificamos como essas mulheres, com diferentes perfis socioeconômicos, aqui analisados a partir de quatro marcadores (raça/cor, estrato sócio-ocupacional, grau de instrução e idade), usaram a rede social Facebook durante a campanha eleitoral, correlacionando tais dimensões com a existência de Página e/ou Perfil, se houve uso contínuo da ferramenta durante a campanha, o número total de publicações, a proporção de publicações relacionadas à própria campanha e o uso de impulsionamento.

As candidatas negras usam o Facebook de maneira diferente das candidatas brancas? Será que as candidatas sem ensino superior completo e de estratos sócioocupacionais mais baixos utilizam o Facebook diferentemente daquelas com maior grau de instrução e pertencentes aos estratos sócio-ocupacionais mais altos? E as candidatas com mais idade em relação às mais jovens? Como dito anteriormente, uma hipótese seria que as redes sociais, por terem acesso inicial gratuito e estarem fora do escopo de controle direto dos partidos políticos, poderiam representar uma alternativa para nivelar diferenças. Ao contrário, se as respostas a essas perguntas forem positivas, será necessário entender quais diferenças são relevantes e se o uso do Facebook reproduz as desigualdades socioeconômicas existentes no mundo offline.

\section{Desigualdades digitais em campanhas eleitorais: do acesso às habilidades de manejo da internet}

Nesta seção, apresentamos os resultados de estudos sobre desigualdades digitais no acesso à internet e às redes sociais e no seu uso, que, assim como a literatura 
precedente, fornecem as lentes para analisar as variáveis selecionadas e os resultados encontrados.

As primeiras discussões apresentadas neste artigo sobre impactos sociais da tecnologia tratam da sua influência na relação do cidadão com o engajamento na política. Para sistematizar o debate, Boulianne (2009, p. 193) faz uma revisão da literatura e uma separação entre os posicionamentos dos estudiosos que, na leitura de Ribeiro, Borba e Hansen (2019, p. 262), podemos encaixar em dois possíveis grupos: os cyberotimistas e os cyberpessimistas. Segundo Boulianne, os primeiros defendem que a internet seria capaz de mobilizar indivíduos desengajados, uma vez que ela ampliaria o acesso à informação e, por conta disso, aumentaria o interesse desses indivíduos em participar da política (p. 194195). Ainda de acordo com essa autora, o segundo grupo de estudiosos entende que a internet não mobilizaria indivíduos desengajados; pelo contrário, só aumentaria desigualdades políticas que já existem no mundo offline e desestimularia o engajamento político, pois essa tecnologia estaria sendo adotada, sobretudo, como forma de entretenimento (p. 193-194). Ribeiro, Borba e Hansen (2019) complementam afirmando que quem já é engajado ficaria mais engajado, e os menos engajados ficariam ainda mais desengajados.

Com base em Anstead e Chadwick (2009, p. 58), pode-se acrescentar que haveria ainda um terceiro grupo que faz contraposição aos cyberotimistas: o dos normalizadores. Partindo de uma análise institucional comparada em pesquisa de campanha na internet, os autores entendem que, para os normalizadores, a internet apenas replica as atuais relações políticas e de poder existentes, ao passo que os otimistas veem na internet uma possibilidade de reforma política e redistribuição de poder. Os normalizadores também afirmam que os recursos disponíveis para os atores políticos (tais como recursos financeiros, midiáticos e sociais) são capazes de condicionar suas habilidades no uso da internet para realizar campanha, traduzindo a força offline que eles têm em vantagens no mundo online.

Fato é que a internet é capaz de reconfigurar ou até reduzir os custos de oportunidade das pessoas a ela conectadas, porém não os neutraliza (Anstead e Chadwick, 2009, p. 57). Há uma ampla literatura que trata dos conceitos da exclusão digital e da desigualdade digital (DiMaggio e Hargittai, 2001; DiMaggio et al., 2004; Guillén e Suárez, 2005; Hargittai, 2002; Zillien e Hargittai, 2009). Com base nela, é possível afirmar que a exclusão digital foi considerada, em um primeiro momento, um debate binário voltado a ter ou não os meios de acessar a internet. Esse debate precisaria ser ampliado para olhar as desigualdades online, resultantes das habilidades offline dos usuários (DiMaggio e Hargittai, 2001; Hargittai, 2002).

A discussão sobre exclusão digital avançou no sentido de considerar a desigualdade de conhecimento no uso das ferramentas digitais, o "knowledge divide" (Várallyai, Herdon e Botos, 2015, p. 365), além de reconhecer que o acesso em si é apenas uma das várias 
fontes de desigualdade que precisam ser analisadas no tema da desigualdade digital (Hargittai e Hsieh, 2013, p. 2). Há, portanto, o reconhecimento da literatura especializada de que a exclusão digital é um fenômeno mais complexo e multidimensional do que se pensava inicialmente, e o termo "desigualdade digital" passou a se referir às disparidades socioeconômicas existentes dentro da "população online", tais como qualidade e custo de conexão e conhecimentos e habilidades para encontrar informações (Stiakakis, Kariotellis e Vlachopoulou, 2009, p. 47-48). Entretanto, interação entre acesso e habilidade ainda é um tema pouco explorado pela literatura tanto brasileira quanto internacional (Ribeiro, Borba e Hansen, 2019).

DiMaggio e Hargittai (2001) identificam cinco dimensões da desigualdade digital, interconectadas: (i) meios técnicos pelos quais as pessoas acessam a internet (por exemplo, qualidade da conexão e de hardware); (ii) autonomia no uso da internet (por exemplo, acesso de casa ou do trabalho, compartilhamento com outras pessoas); (iii) habilidade da pessoa em usar a internet; (iv) apoio social ao qual o usuário de internet pode recorrer; e ( $v$ ) propósito com o qual a pessoa usa a internet (p. 8).

Segundo esses autores, a primeira dimensão - meios técnicos - sinaliza que quem não tem formas eficientes de acessar a internet, que em geral são mais caras, não consegue explorar todo o conteúdo online disponível, reduzindo os benefícios que seriam possíveis com a internet, o tempo de uso e a aquisição de habilidades. A segunda dimensão, autonomia, aponta fatores geográficos em que o acesso à internet disponível é mais restrito, como em bibliotecas públicas, e de pior qualidade, principalmente em áreas rurais (DiMaggio e Hargittai, 2001, p. 8-9). Em relação a essas duas dimensões, poderíamos acrescentar a questão atual a respeito de o acesso se dar por meio de celular ou de computador, por um pacote de dados restrito ou por uma conexão rápida, estável e sem limitações de dados. Os autores reconhecem que os estudos demonstram forte associação de nível educacional, raça e renda com disponibilidade de internet em casa, e entendem que, entre as pessoas com esse acesso, quanto maior a autonomia, maiores são os benefícios ${ }^{12}$ que os usuários adquirem (DiMaggio e Hargittai, 2001, p. 10).

A terceira dimensão - habilidades - indica que a diferenciação entre usuários pode ser feita por meio da análise do nível educacional e das habilidades técnicas: quanto maior o nível educacional e o domínio das habilidades técnicas necessárias, mais e melhor a ferramenta será explorada pelo usuário para os propósitos que Ihe interessam (DiMaggio e Hargittai, 2001, p. 10-11). A quarta dimensão - apoio social - sugere que amigos e/ou familiares usuários de novas tecnologias são responsáveis por motivar novas pessoas a adotarem esses meios também. Por fim, a quinta dimensão - propósito do uso - significa

\footnotetext{
12 Os autores não definem expressamente o que consideram ser benefícios nesse contexto. Porém, a partir da leitura de seu artigo, é possível apontar que benefícios consistem na possibilidade de o usuário buscar, encontrar e salvar informações de forma rápida e quando tem necessidade. De forma mais concreta, há de se falar na possibilidade de encontrar oportunidades de educação, emprego, cuidados com a saúde, além de participação e criação de espaços de discussão, inclusive política.
} 
que, quanto mais sofisticado é o uso - por exemplo, quando se busca o aprimoramento de habilidades, oportunidades de emprego e informações sobre questões políticas, em vez do mero consumo de entretenimento -, mais habilidades são necessárias, conectando-se, assim, com a terceira dimensão aqui apresentada.

A dimensão das habilidades é a que mais diretamente se liga à análise aqui empreendida. Essa dimensão trata de uma espécie de "competência" que consiste na capacidade de responder pragmática e intuitivamente aos desafios e oportunidades de forma que o potencial do ambiente digital seja mais bem explorado (DiMaggio e Hargittai, 2001 , p. 11). Tais conhecimentos podem ser influenciados pelos aparatos sociais de que a pessoa pode dispor ou não, como o nível educacional e financeiro, indicando que há uma relação entre status socioeconômico e a posse de recursos digitais. Ou seja, as desigualdades sociais existentes no mundo offline podem reforçar as desigualdades digitais (Hargittai e Hsieh, 2013, p. 3), o que, por sua vez, afeta o uso dos recursos digitais (p. 9). A tese que os autores apresentam é de que as habilidades e competências no uso da internet estão ligadas à satisfação dos usuários com a experiência de usá-la, que, se for positiva, permite que fiquem mais tempo na internet e, por sua vez, desenvolvam habilidades adicionais (DiMaggio e Hargittai, 2001, p. 11).

Para os fins do presente artigo, a dimensão das habilidades, trabalhada na literatura de desigualdade digital, é a lente teórica adotada para compreender as diferenças no uso de ferramentas como a Página e o Perfil do Facebook entre as candidatas ao cargo de deputado federal pelo estado de São Paulo nas eleições de 2018. Todas as variáveis coletadas e analisadas, e que serão detalhadamente explicadas na próxima seção, guardam essa dimensão de habilidade.

No Brasil, os estudos acerca do Facebook como ferramenta de campanha são mais centrados na análise do uso dessa ferramenta em eleições majoritárias, como mostraremos a seguir. Ainda há poucos estudos focados no uso do Facebook em eleições proporcionais brasileiras e menos ainda em mulheres candidatas em eleições proporcionais, mas a análise de alguns estudos nacionais e da experiência de alguns outros países pode ajudar a levantar hipóteses sobre a forma como essa rede social é usada durante as campanhas eleitorais no Brasil.

Em um estudo conduzido na Nova Zelândia, são analisadas as diferenças de frequência e de comportamento entre as postagens no Facebook dos candidatos ao parlamento nas eleições gerais do país em 2011 (Ross, Fountaine e Comrie, 2014). Nas 1.148 postagens totais feitas ao longo da campanha, as autoras identificam que as mulheres tendem a postar com mais frequência conteúdos relacionados a pautas de campanhas do que os homens.

Gulati e Williams (2013) observam o uso do Facebook nas eleições de 2012 para o Congresso dos Estados Unidos com o objetivo de identificar o que diferenciava o pequeno substrato de candidatos que optaram por não usar a rede social da grande maioria que 
usou. O estudo conclui que um dos grandes marcadores de diferença foram os recursos financeiros e a idade, ou seja, os candidatos que não tinham presença no Facebook eram em sua maioria independentes (sem vinculação partidária), com pouco financiamento e mais velhos. Ainda assim, uma vez que a adoção do Facebook entre candidatos norteamericanos é quase universal (mais de $90 \%$ dos candidatos em disputa utilizaram a ferramenta Página), o estudo ressalta que a mera utilização da ferramenta não indica mais competitividade, mas sim a forma como o candidato a utiliza.

No Brasil, o uso de redes sociais em campanhas eleitorais ainda está em processo de consolidação. Braga e Carlomagno (2018) sistematizam a literatura acerca do uso da internet em campanhas eleitorais no país e, com base nessa sistematização, indicam momentos de suma importância para a compreensão do uso das tecnologias digitais no processo eleitoral brasileiro, entre os quais destacamos quatro: os anos de 1998, 2010, 2012 e 2014. De acordo com os autores, as primeiras experiências de uso da internet em campanha eleitoral ocorreram em 1998, a partir da utilização de websites pelos candidatos. O uso da web foi se tornando mais avançado com o passar das eleições, aumentando o número de candidatos à presidência que começaram a utilizá-la; além disso, a interatividade dos websites também passou por transformações. A partir de 2010, cessaram as restrições relacionadas ao uso das mídias sociais no Brasil, restrições essas criadas nas eleições de 1998. Após a queda dessas limitações, nas eleições de 2012 o Facebook começou a ser utilizado mais intensamente pelos candidatos e, nas eleições subsequentes, em 2014, essa rede social se tornou a principal ferramenta de campanha na internet, sendo mantida nas eleições de 2016 como a rede de maior impacto.

Com base no exposto, notamos que uma parcela dos estudos nacionais que analisam o uso do Facebook para fins eleitorais por parte dos candidatos que disputam algum cargo eletivo se concentra em disputas majoritárias e direciona seu olhar para a análise de conteúdo das publicações (Gonçalves e Ferreira, 2013; Ituassu et al., 2014; Souza, 2014; Massuchin e Tavares, 2015; Eufrauzino, 2015; Rossini et al., 2016; Souza e Marques, 2016; Penteado, Pereira e Fiacadori, 2016; Miola e Carvalho, 2017; Borba, 2019). Além do foco no conteúdo, alguns estudos também analisam a participação de eleitores (Silva e Silva, 2015; Maia, 2019), a integração do Facebook com outros sites (Aggio e Reis, 2013), o discurso utilizado e a integração com outras redes (Panke e Thauny, 2013) e uso do Facebook e redes de apoio (Albuquerque et al., 2016). Apenas dois dos estudos levantados abordam as eleições proporcionais, mais especificamente a disputa para o cargo de deputado federal, concentrando-se na análise de conteúdo de publicações (Santos, 2017) e na análise de conteúdo e interação (Murta et al., 2017)

Murta et al. (2017) analisam a interação e a participação nas fanpages (Páginas) de Facebook de oito candidatos ao cargo de deputado federal nas eleições de 2014, buscando compreender quais tipos de postagens são privilegiadas nas suas Páginas e qual tipo tem mais interações. A pesquisa abrangeu os 33 últimos dias de propaganda eleitoral 
na internet e analisou 840 publicações, assim como seu número de curtidas, compartilhamentos e comentários. Utilizando o software Digicamp, os pesquisadores rastrearam, coletaram, organizaram e indexaram essas publicações em sete categorias: registro de atividades, apoio de terceiros, pedido de voto, plataforma de campanha, feitos do passado, evento, pessoal. Os autores concluíram que um candidato interessado em mais curtidas, comentários ou compartilhamentos, em tese, deve se preocupar mais com a qualidade do que com a quantidade de postagens, e que, quanto mais seguidores tem um candidato, maior a possibilidade de interações.

Santos (2017), por sua vez, foca sua pesquisa na compreensão do uso do Facebook por dois candidatos eleitos ao cargo de deputado federal em 2014. A autora coletou as publicações de ambos os candidatos em suas fanpages durante o período de campanha eleitoral (entre 6 de julho e 5 de outubro de 2014), transformando todas as publicações em arquivos salvos em formato PDF para posterior submissão ao software Atlas TI. Uma amostra correspondente a 13 dias de campanha foi utilizada como base e os conteúdos das publicações foram analisados a partir das seguintes categorias: "a coesiva - indica o sentimento de grupo ou a simples presença na mídia -, a afetiva - expressa humor, emoção e autorrevelação -, e a interativa - pressupõe que os agentes respondam ou façam perguntas, citem ou concordem com outras postagens" (p. 106).

Ao efetivar a análise das publicações e entrevistar os candidatos, os resultados da autora mostram que ambos os candidatos tiveram uma presença social predominantemente coesiva no Facebook, mas cada um deles enfoca a rede social de modo diferente. Um dos candidatos focou na campanha física, por não considerar o seu eleitorado engajado em discussões com cunho político na internet, deixando o espaço online em segundo plano; seu assessor foi o responsável por sua campanha online, utilizando o celular para realizar as publicações, de forma a priorizar a agilidade das postagens, conforme argumenta a autora (Santos, 2017, p. 108). Em contrapartida, o outro candidato buscou se adaptar às tecnologias de comunicação, contando com o suporte de uma equipe para a realização da campanha (jornalista, fotógrafo, publicitário, social media e chefe de gabinete); mas, diferentemente do primeiro candidato, havia demora para a publicação dos conteúdos, o que pode ter comprometido o envolvimento dos seguidores.

Santos (2017) conclui que um dos candidatos utilizou o Facebook como uma ferramenta complementar às outras táticas de campanha, ao passo que o outro direcionou sua campanha ao Facebook e ao Twitter. Todavia, nenhuma dessas campanhas se encaixa no conceito de "cybercampanhas", pois, conforme explica a autora, "não se observam estratégias voltadas especificamente para o ambiente social virtual" (p. 110).

Os achados do presente artigo dialogam com essas pesquisas e buscam avançar a compreensão sobre o uso das redes sociais para fins de campanha eleitoral em eleições proporcionais e, em especial, entre mulheres candidatas ao suscitar novas reflexões sobre o uso e a qualidade do uso do Facebook no processo eleitoral e ao lançar mão de novos 
critérios de análise, direcionando o olhar para as desigualdades existentes entre as candidaturas de mulheres em ambiente offline e suas repercussões em ambiente online.

\section{Nota metodológica}

Com o objetivo de contribuir para os estudos que analisam como o Facebook tem sido utilizado em campanhas eleitorais, em particular entre mulheres candidatas, procuramos entender se o seu uso reduz as desigualdades estruturais presentes no mundo offline ou acaba por reproduzi-las em um contexto já marcado por diversas desigualdades, como é o caso do processo eleitoral. Para tanto, realizamos o monitoramento das 465 candidatas que chegaram até as urnas na disputa pelas cadeiras da Câmara Federal pelo estado de São Paulo.

O Facebook foi escolhido pelo fato de ser essa a rede social mais utilizada pelos brasileiros - aproximadamente 127 milhões $^{13}$ - e por proporcionar aos usuários uma ampla variedade de meios de difusão de informações, como a possibilidade de uso do Perfil pessoal, criação de uma Página, publicação de diferentes tipos de conteúdo, como textos, imagens, vídeos, links, criação de eventos e utilização de instrumentos como o impulsionamento. A opção por analisar as candidatas pelo estado de São Paulo se deu por esse ser o maior colégio eleitoral do país e pelo fato de as mulheres serem mais afetadas pelas desigualdades no momento da campanha eleitoral. O crescimento da relevância de campanhas online poderia ser uma possível alternativa para contornar essas desigualdades. E, por este artigo estar inserido em uma pesquisa mais ampla sobre as condições de inserção das mulheres em disputas eleitorais, focamos nossa análise no gênero feminino, bem como na raça/cor das candidatas.

O processo de monitoramento foi realizado manualmente por uma equipe de 15 pesquisadoras(es). A opção pela coleta manual em detrimento do uso de ferramenta automatizada de web scraping foi feita em decorrência das restrições ${ }^{14}$ criadas pelo Facebook no que concerne ao acesso aos dados por meio desse último tipo de coleta.

O monitoramento do uso das ferramentas pelas candidatas foi realizado semanalmente pela equipe, no período de 16 de agosto a 7 de outubro de 2018. As seguintes informações foram coletadas e são a base deste artigo: endereço da

\footnotetext{
13 Informação disponível em: <https://www1.folha.uol.com.br/tec/2018/07/facebook-chega-a-127-milhoesde-usuarios-mensais-no-brasil.shtml>. Acesso em: 19 dez. 2019.

14 Buscamos, inicialmente, a realização de coleta automatizada para facilitação do acesso aos dados necessários à pesquisa. Todavia, verificamos que a API (Application Programming Interface) do Facebook sofreu alterações após o caso da Cambridge Analytica, culminando em restrições para a coleta automatizada de dados. Passou a ser necessária a aprovação dos aplicativos utilizados e, mesmo com essa aprovação, manteve-se a restrição para captação de algumas informações. Em decorrência dessa limitação, optamos pela coleta manual para que a pesquisa pudesse ser concretizada.
} 
Página/Perfil ${ }^{15}$, número total de publicações da candidata e número de publicações relacionadas à própria campanha. Após o período eleitoral, coletamos ainda o número de impulsionamentos de publicações de cada uma das candidatas, por meio da Biblioteca de Anúncios do Facebook ${ }^{16}$, ferramenta disponibilizada pela própria rede social e que permitiu ao público acesso a todos os impulsionamentos efetivados no período de campanha eleitoral.

Optamos por monitorar as ferramentas Página e Perfil, pois há importantes diferenças entre elas. Os Perfis possuem limitação no que concerne ao número de "amigos" que podem ser adicionados; as publicações podem estar restritas aos seus amigos, não permitindo acesso público às informações e publicações do usuário; e trata-se de uma ferramenta administrada por um único usuário. Diferentemente, as Páginas podem ser administradas por diversos usuários, as postagens se tornam públicas, ampliando a possibilidade de acesso por parte dos usuários do Facebook, e não há limitação quanto ao número de seguidores. Uma diferenciação de extrema relevância é que os impulsionamentos podem ser realizados apenas por meio das Páginas. Pelas distinções elencadas e levando em conta o contexto eleitoral, consideramos neste artigo que a Página é uma ferramenta que possibilita um uso mais profissional quando comparada ao Perfil.

O impulsionamento é uma funcionalidade paga, diferentemente da criação de Páginas e Perfis, que é gratuita. Seu uso visa ampliar a difusão de postagens para públicos que normalmente não teriam acesso a elas, conferindo maior alcance e visibilidade a esse conteúdo. Além disso, no contexto da campanha eleitoral de 2018, o uso do impulsionamento foi regulado pela Justiça Eleitoral, que criou regras ${ }^{17}$ específicas para a

\footnotetext{
15 Segundo o Facebook, "um Perfil é um local no Facebook onde você pode compartilhar informações sobre si mesmo, como interesses, fotos, vídeos, cidade atual e cidade natal". É preciso ter um Perfil para criar uma Página ou gerenciar Páginas de terceiros.

Em linhas gerais, Páginas "são locais no Facebook que artistas, figuras públicas, empresas, marcas, organizações e ONGs usam para se conectar aos fãs ou clientes. Quando uma pessoa curte ou segue uma Página no Facebook, ela começa a ver as atualizações dessa Página no Feed de Notícias". Disponível em: <https://www.facebook.com/help/337881706729661 ?helpref=search\&sr=2\&query=0\%20que\%20é\%20u m\%20perfil>. Acesso em: 19 dez. 2019.

16 Endereço da Biblioteca de Anúncios: <https://www.facebook.com/ads/archive/>. Acesso em: 20 nov. 2018.

17 Resolução no 23.551/2017 (TSE), art. 24. É vedada a veiculação de qualquer tipo de propaganda eleitoral paga na internet, excetuado o impulsionamento de conteúdos, desde que identificado de forma inequívoca como tal e contratado exclusivamente por partidos políticos, coligações e candidatos e seus representantes (Lei no 9.504/1997, art. 57-C, caput).

$\S 2^{\circ} \mathrm{A}$ violação do disposto neste artigo sujeita o responsável pela divulgação da propaganda ou pelo impulsionamento de conteúdos e, quando comprovado seu prévio conhecimento, o beneficiário à multa no valor de $\mathrm{R} \$ 5.000,00$ (cinco mil reais) a $\mathrm{R} \$ 30.000,00$ (trinta mil reais) ou em valor equivalente ao dobro da quantia despendida, se esse cálculo superar o limite máximo da multa (Lei no 9.504/1997, art. 57-C, § 20). $\S 3^{\circ} \mathrm{O}$ impulsionamento de que trata o caput deste artigo deverá ser contratado diretamente com o provedor da aplicação de internet com sede e foro no País, ou de sua filial, sucursal, escritório, estabelecimento ou representante legalmente estabelecido no País e apenas com o fim de promover ou beneficiar candidatos ou suas agremiações (Lei no 9.504/1997, art. 57-C, § $3^{\circ}$ ).

$\S 40 \mathrm{O}$ representante do candidato a que alude o caput se restringe à pessoa do administrador financeiro da respectiva campanha.
} 
utilização dessa ferramenta, as quais deveriam ser seguidas à risca pelas candidaturas sob pena de cometerem crime eleitoral. Assim, o uso do impulsionamento requer não só o conhecimento prévio de uma série de normas jurídicas, como também uma habilidade específica para a utilização legal das funcionalidades oferecidas pelo Facebook.

Outras informações utilizadas neste artigo foram coletadas no repositório de dados eleitorais disponibilizado pelo Tribunal Superior Eleitoral (TSE), tais como idade, grau de instrução e raça/cor das candidatas. A partir do dado de ocupação, igualmente disponibilizado pelo TSE, enquadramos cada uma das ocupações em cinco diferentes estratos sócio-ocupacionais: (i) baixo, (ii) médio-baixo, (iv) médio ( $\mathrm{v}$ ) médio-alto e (vi) alto, com base em classificação utilizada por Jannuzzi (2003) ${ }^{18}$. Desse modo, essa variável foi operacionalizada para marcar diferenças de classe entre as candidatas em termos das ocupações declaradas à Justiça Eleitoral.

Embora a disputa tenha sido iniciada por 528 mulheres, durante o processo de análise de suas candidaturas, algumas renunciaram e outras foram impedidas de concorrer por terem as candidaturas indeferidas. Assim, apenas as 465 candidatas aptas, deferidas e que tiveram os nomes incluídos na urna foram acompanhadas durante todas as sete semanas. Nos casos de indeferimento ou renúncia, o monitoramento da candidata cessava na semana em que fosse divulgada a sua renúncia ou o indeferimento.

Entre todas as mulheres que concorreram ao cargo, foram encontradas as Páginas de 299 candidatas e os Perfis de 375 em ao menos uma das semanas de campanha. Mas nem todas tiveram Página ou Perfil durante todo o processo eleitoral: apenas 246 candidatas tiveram Página durante as sete semanas de campanha e 367 tiveram Perfil durante esse período. Fala-se em Páginas e Perfis encontrados porque foi realizada a busca na seção "pesquisar" disponibilizada no Facebook, utilizando o nome completo da candidata, nome de urna ou diferentes combinações com partes dos nomes. E os resultados foram comparados com as fotos do TSE das respectivas candidatas, para checar se foi encontrada a pessoa correta. Em muitos casos, não houve qualquer correspondência entre os nomes buscados e a existência de Página ou Perfil. Além disso, a cada semana de monitoramento, as candidatas que não foram encontradas no Facebook na semana anterior tiveram seus nomes novamente pesquisados. Assim, pudemos verificar casos em que candidatas criaram sua Página ou seu Perfil em momento posterior ao do início do processo eleitoral.

$\S 50$ Todo impulsionamento deverá conter, de forma clara e legível, o número de inscrição no Cadastro Nacional da Pessoa Jurídica (CNPJ) ou o número de inscrição no Cadastro de Pessoas Físicas (CPF) do responsável, além da expressão "Propaganda Eleitoral".

18 Uma das opções de ocupação é "outros", e 141 candidatas assinalaram essa categoria. Como se trata de um número elevado de candidatas, correspondendo a $26,7 \%$ do número total de mulheres concorrendo ao cargo, buscamos as respostas para essa categoria "outros" por meio de solicitação à Ouvidoria do TSE no dia 14 de fevereiro 2019. No dia $1^{\circ}$ de março 2019, recebemos a seguinte resposta via e-mail: "A informação a respeito de ocupação é autodeclarada e não é possível declarar a opção 'outros'". Diante disso, as candidatas desse grupo não tiveram suas ocupações classificadas, impedindo a sua análise. 
Para identificar o acesso ao Facebook e o seu modo de uso por parte das candidatas, foram utilizados cinco descritores para construir as variáveis dependentes:

(i) Acesso (probabilidade de ter Página e/ou Perfil em ao menos uma das semanas de campanha): assume valor 1 para as candidatas que tiveram uma Página ou Perfil ativo identificado em pelo menos uma semana de monitoramento e valor 0 em caso contrário;

(ii) Uso contínuo (probabilidade de manter Página e/ou Perfil durante as sete semanas de campanha): assume valor 1 para as candidatas que tiveram uma Página ou Perfil ativo identificado em todas as sete semanas de monitoramento, e valor 0 em caso contrário;

(iii) Intensidade (quantidade total de publicações realizadas na Página e/ou no Perfil): logaritmo natural da soma de todas as publicações realizadas na Página ou Perfil durante as sete semanas de monitoramento. Importante salientar que a soma das publicações das candidatas durante todo o período eleitoral, independentemente de seus conteúdos, é igual a 55.543.

(iv) Foco (porcentagem de publicações correspondentes à divulgação da própria campanha): razão entre a quantidade de postagens em que a candidata explicitamente faz campanha pela sua candidatura e a quantidade total de postagens na Página e/ou no Perfil. Foram consideradas postagens da própria campanha apenas as postagens na Página e/ou no Perfil próprios da candidata (feitas por ela mesma ou por terceiros) que se referiam explicitamente à candidatura através de divulgação de seu nome, número de urna e/ou pedido evidente de voto. Essa menção explícita poderia ter sido feita através de texto da postagem, imagem que mostrasse claramente os elementos citados acima (como a foto de um santinho) ou vídeo em que houvesse menção direta à candidata, ao número de urna e/ou pedido explícito de voto. Algumas(ns) leitoras(es) poderiam supor que toda e qualquer postagem de uma candidata no período eleitoral seria uma postagem com o objetivo de promover a campanha. Acontece que as observações do campo de pesquisa nos mostraram que postagens de cunho privado, sem nenhuma referência à candidatura, foram frequentes. Embora reconheçamos que cada publicação em uma rede social, independentemente de seu conteúdo, tem um papel na construção da imagem de uma pessoa, o interesse dessa análise é entender com que frequência a candidata fez postagens reforçando explicitamente a sua candidatura, pois muitas Páginas não eram utilizadas apenas para a disputa eleitoral, ou não foram criadas necessariamente com essa finalidade. Há candidatas, por exemplo, que já possuíam Página na qual divulgavam informações sobre sua profissão ou sobre outros temas que não as eleições e aproveitaram esse espaço para divulgar a própria campanha. Assim, a escolha por só considerar "de campanha" as postagens que tivessem um pedido explícito de voto ou que mostrassem - através de texto, fala (mensagem de voz ou vídeo) ou imagem (fotografia, meme, santinho etc.) - o número de urna da candidata foi a que nos pareceu mais adequada para diferenciar essas postagens das demais e padronizar a variável entre as candidatas analisadas. A soma das 
publicações concernentes à própria campanha das candidatas durante todo o período eleitoral foi igual a 31.645 , o que corresponde a aproximadamente $57 \%$ de todas as publicações.

(v) Impulsionamento (probabilidade de utilização de impulsionamento de publicações): assume valor 1 para todas as candidatas que tiveram pelo menos uma postagem com impulsionamento pago durante as sete semanas de campanha e valor 0 em caso contrário.

Analisamos os possíveis efeitos que as seguintes variáveis independentes poderiam exercer sobre as variáveis dependentes: (1) escolaridade (ensino superior completo), (2) raça (raça/cor branca), (3) estratp sócio-ocupacional (pertencer a estrato sócioocupacional alto) e (4) idade. Todas elas, com exceção da idade, são variáveis binárias que assumem o valor 1 caso a candidata apresente a respectiva característica.

O objetivo da análise foi identificar se o Facebook foi um ambiente no qual as desigualdades socioeconômicas entre as candidatas ao cargo de deputado federal por São Paulo em 2018 foram reproduzidas ou mitigadas no processo de campanha eleitoral. Para os fins deste estudo, o uso das ferramentas Página e Perfil demonstraria a mitigação das desigualdades estruturais da sociedade se encontrássemos formas de utilização parecidas entre diferentes grupos de candidatas. O fato de características como ter menos idade, ter ensino superior completo, declarar-se branca e pertencer a estrato sócio-ocupacional alto não serem significantes para um uso mais intenso da Página e/ou do Perfil no Facebook durante a campanha é sinal de que essas ferramentas podem ajudar a equalizar as condições de campanha. Caso contrário, elas podem reproduzir desigualdades estruturais.

As variáveis dependentes que medem acesso, uso contínuo, intensidade, foco e impulsionamento denotam medidas de habilidades das candidatas ao operar a ferramenta analisada. Abrir uma Página ou um Perfil no Facebook demanda um conhecimento mínimo de como essa rede social funciona e o que é preciso para ter acesso a ela. É também importante deter habilidades específicas para usar as múltiplas funções das ferramentas disponíveis dentro da plataforma de modo mais focado na campanha eleitoral. As variáveis que medem a manutenção do uso das ferramentas durante todo o período eleitoral (uso contínuo) e a quantidade absoluta de postagens estão também relacionadas com possíveis habilidades que as candidatas possuem. Além disso, manter uma Página e/ou um Perfil ativos por sete semanas e realizar postagens frequentes ou focadas na própria campanha demandam intenso tempo de dedicação, o que nem sempre está à disposição de todas as candidatas, tendo em vista as diferentes condições socioeconômicas das quais elas partem. Finalmente, a variável de impulsionamento foi operacionalizada para medir quais candidatas efetivamente conseguiram acessar essa ferramenta, já que isso também demandaria habilidades específicas, como discutido acima ${ }^{19}$.

\footnotetext{
${ }^{19}$ A escolha por uma variável binária, que mede apenas se o impulsionamento foi feito ou não, nos pareceu mais adequada para comparar as candidatas em termos de suas habilidades/competências digitais. Uma alternativa teria sido usar uma variável contínua, que medisse a quantidade de postagens que cada candidata
} 
Entre as variáveis explicativas, possuir ensino superior completo é uma indicação da facilidade que uma candidata terá em absorver os conhecimentos necessários para operacionalizar as ferramentas no Facebook. Supõe-se que ter uma escolaridade mais alta esteja correlacionado com maiores habilidades. Assim, espera-se que haja uma relação positiva entre possuir ensino superior completo e nossas variáveis dependentes. 0 contrário deve ocorrer para a variável idade. Pessoas com mais idade tendem a ter mais dificuldade para absorver novos conhecimentos relacionados a novas tecnologias, ou seja, teriam menor habilidade para operacionalizar as ferramentas. Espera-se que a idade se relacione negativamente com nossas variáveis dependentes. As variáveis de raça/cor e estrato sócio-ocupacional também marcam divisões de grupos que possivelmente tenham diferentes habilidades na utilização das ferramentas analisadas. É sabido que no Brasil a escolaridade de cidadãos negros e dos mais pobres é mais baixa (menor acesso à educação infantil, maior evasão no ensino básico, menor ingresso no ensino superior), além de terem de enfrentar outras adversidades como a necessidade de trabalhar em idade precoce, impossibilidade de dedicação de tempo para atividades que não sejam as relacionadas à obtenção de renda ou afazeres e cuidados domésticos, e condições piores de moradia e segurança pessoal. Esses fatores podem ser fundamentais para determinar as decisões das pessoas em termos de se, como e por quanto tempo utilizam ferramentas de redes sociais, principalmente em contexto eleitoral.

Dadas as considerações acima, podemos definir as hipóteses deste artigo como sendo:

- H1: ter ensino superior se correlaciona positivamente com as variáveis dependentes;

- H2: a idade das candidatas se correlaciona negativamente com as variáveis dependentes;

- H3: ter declarado raça/cor branca se correlaciona positivamente com as variáveis dependentes;

- H4: pertencer aos estratos sócio-ocupacionais mais altos se correlaciona positivamente com as variáveis dependentes.

A estratégia de análise foi o uso de regressões multivariadas. Usamos regressões logísticas para as variáveis dicotômicas - (i) acesso, isto é, tem Página ou Perfil; (ii) uso contínuo, isto é, manteve Página ou Perfil; e (v) impulsionamento - e regressões por mínimos quadrados ordinários robustos para (iii) intensidade e (iv) foco.

Os coeficientes representam a variação estimada na variável dependente dado um aumento unitário na variável independente, mantendo as demais fixas. Seu valor absoluto precisa ser analisado com cautela, em especial o das regressões logísticas. Quando a variável dependente estiver em "log", a interpretação passa a ser em termos percentuais.

impulsionou, se o foco fosse mensurar diferenças relacionadas à quantidade de recursos disponíveis para serem usados nessa atividade, o que não era o objetivo neste artigo. 
Isso quer dizer que, caso a variável dependente esteja em "log" (modelo log-nível), um aumento unitário da variável explicativa gera um efeito percentual na variável dependente no valor de seu coeficiente multiplicado por 100 (Wooldridge, 2013, p. 44). Nas regressões logísticas, é preciso calcular o Efeito Marginal na Média (EFM) - elasticidades marginais calculadas nas médias das variáveis independentes - depois de estimar os coeficientes das regressões para podermos interpretar o impacto estimado do aumento da variável independente sobre a dependente (p. 542). Variáveis explicativas binárias (caso de estrato sócio-ocupacional alto, raça/cor branca e ensino superior) também demandam uma interpretação diferenciada dos coeficientes (p. 217).

A significância estatística indica se o impacto da variável independente sobre a dependente é estatisticamente diferente de zero, dado um nível de significância e o desviopadrão da variável. Isso quer dizer que, se construirmos um intervalo de confiança para a estimativa do impacto da variável independente sobre a dependente e o valor zero não estiver contido nesse intervalo, poderemos rejeitar a hipótese nula de que o impacto é igual a zero. Os valores dos limites superior e inferior dos intervalos de confiança dependem do nível de significância. Um nível de significância de X\% representa que, se realizássemos repetidamente o mesmo teste usando amostras diferentes, obteríamos resultados dentro do intervalo de confiança em (100-X)\% das vezes. Para nossas análises, utilizamos níveis de significância de 1\%, 5\% e $10 \%$.

\section{Resultados do uso do Facebook nas campanhas das candidatas: redução ou reprodução das desigualdades?}

Nesta seção, apresentamos os resultados das regressões, com o objetivo de responder à seguinte pergunta: o uso das ferramentas Página e Perfil do Facebook na campanha contribuiu para a reprodução de desigualdades presentes em ambiente offline ou atuou de modo a mitigá-las durante as eleições de 2018?

A Tabela 1 sintetiza os achados. As linhas representam as variáveis dependentes e as colunas, as variáveis explicativas. Começamos com a análise dos resultados para a ferramenta Página. Encontramos uma correlação importante entre as variáveis explicativas analisadas e a utilização dessa ferramenta. Ter ensino superior e declarar-se branca mostraram-se significantes no acesso, no uso contínuo e na intensidade de publicações. 0 estrato sócio-ocupacional também se mostrou importante para as duas primeiras variáveis e foi a única a se correlacionar com o foco do uso da ferramenta para a campanha. A idade foi negativamente correlacionada com o uso contínuo e a intensidade do uso da Página.

Em relação à utilização da ferramenta Perfil, as variáveis explicativas não mostraram uma correlação tão intensa quanto para a ferramenta Página. As variáveis estrato sócio-ocupacional e idade foram as únicas a apresentar significância estatística, para apenas uma das dependentes (porcentagem de postagens de campanha), com 
coeficientes muito próximos de zero. Isso pode ser sinal de que ainda exista algum diferencial de classe e de geração no uso dessa rede social durante a campanha.

Realizamos ainda uma análise do impulsionamento de conteúdo, identificando as candidatas que usaram esse serviço em suas Páginas. O resultado da regressão mostra uma correlação com todas as nossas variáveis independentes. Ensino superior, raça/cor branca e estrato sócio-ocupacional alto se correlacionaram positivamente com o impulsionamento de conteúdo com coeficientes significantes. A idade se correlacionou negativamente, também com significância estatística.

Tabela 1

Resultados das regressões

\begin{tabular}{|c|c|c|c|c|c|c|c|c|}
\hline & & Constante & $\begin{array}{c}\text { Ensino } \\
\text { superior }\end{array}$ & Branca & $\begin{array}{c}\text { Estrato } \\
\text { alto }\end{array}$ & Idade & $\mathbf{N}$ & $\mathbf{R}^{2}$ \\
\hline \multirow{8}{*}{ Página } & \multirow{2}{*}{ Acesso } & 0.292 & $0.461 * *$ & $0.555 * * *$ & $0.908 * * *$ & -0.014 & \multirow{2}{*}{465} & \multirow{2}{*}{0.073} \\
\hline & & $(0.462)$ & $(0.211)$ & $(0.211)$ & $(0.216)$ & $(0.008)$ & & \\
\hline & \multirow{2}{*}{ Uso contínuo } & 0.131 & $0.534 * * *$ & $0.440 * *$ & $0.931 * * *$ & $-0.021 * *$ & \multirow{2}{*}{465} & \multirow{2}{*}{0.080} \\
\hline & & $(0.448)$ & $(0.205$ & $(0.209)$ & $(0.205)$ & $(0.008)$ & & \\
\hline & \multirow{2}{*}{ Intensidade } & $3.336 * * *$ & $0.591 * * *$ & $0.370 * *$ & 0.225 & $-0.011^{*}$ & \multirow[b]{2}{*}{291} & \multirow{2}{*}{0.089} \\
\hline & & $(0.348)$ & $(0.172)$ & $(0.179)$ & $(0.166)$ & $(0.006)$ & & \\
\hline & \multirow{2}{*}{ Foco } & $0.842 * * *$ & 0.033 & -0.039 & $0.052 *$ & -0.001 & \multirow{2}{*}{299} & \multirow{2}{*}{0.028} \\
\hline & & $(0.057)$ & $(0.034)$ & $(0.030)$ & $(0.031)$ & $(0.001)$ & & \\
\hline \multirow{8}{*}{ Perfil } & \multirow{2}{*}{ Acesso } & $0.932^{*}$ & 0.018 & 0.063 & 0.318 & 0.006 & \multirow{2}{*}{465} & \multirow{2}{*}{0.005} \\
\hline & & $(0.536)$ & $(0.248)$ & $(0.248)$ & $(0.252)$ & $(0.010)$ & & \\
\hline & \multirow{2}{*}{ Uso contínuo } & $0.889^{*}$ & 0.087 & 0.069 & 0.312 & 0.004 & \multirow{2}{*}{465} & \multirow{2}{*}{0.005} \\
\hline & & $(0.520)$ & $(0.240)$ & $(0.241)$ & $(0.244)$ & $(0.009)$ & & \\
\hline & \multirow{2}{*}{ Intensidade } & $4.176 * * *$ & -0.075 & 0.058 & 0.151 & -0.010 & \multirow{2}{*}{349} & \multirow{2}{*}{0.008} \\
\hline & & $(0.375)$ & $(0.177)$ & $(0.185)$ & $(0.177)$ & $(0.007)$ & & \\
\hline & \multirow{2}{*}{ Foco } & $0.573 * * *$ & 0.023 & 0.015 & $0.095 * * *$ & $-0.003 * *$ & \multirow{2}{*}{375} & \multirow{2}{*}{0.043} \\
\hline & & $(0.075)$ & $(0.033)$ & $(0.035)$ & $(0.033)$ & $(0.001)$ & & \\
\hline \multirow{2}{*}{ Geral } & \multirow{2}{*}{ Impulsionamento } & $-1.442 * *$ & $1.010 * * *$ & $0.656 * *$ & $1.125 * * *$ & $-0.035 * * *$ & \multirow{2}{*}{394} & \multirow{2}{*}{0.134} \\
\hline & & $(0.645)$ & $(0.308)$ & $(0.313)$ & $(0.295)$ & $(0.012)$ & & \\
\hline
\end{tabular}

Fonte: Elaboração própria com base em dados do TSE e no monitoramento de Páginas e Perfis de candidatas no Facebook. Significância: *** $0.01 * * 0.05 * 0.10$.

Por um lado, ter um Perfil no Facebook não depende tanto das características pessoais das candidatas, possivelmente por essa plataforma ter se popularizado na sociedade brasileira e seu uso ter um caráter mais pessoal do que profissional. Por outro, a utilização de uma Página e do impulsionamento de conteúdos se correlacionou com o pertencimento a classes sócio-ocupacionais mais privilegiadas e ao grupo de candidatas mais jovens.

Passamos a analisar os efeitos marginais das variáveis explicativas sobre as dependentes para identificar a magnitude dessa influência. A Tabela 2 indica esses valores. Os impactos que não tiveram coeficientes estatisticamente significantes ou muito próximos de zero foram desconsiderados. Assim, apresentamos os efeitos marginais das variáveis explicativas apenas sobre a ferramenta Página e o impulsionamento. 
Tabela 2

Efeitos marginais das variáveis explicativas sobre as dependentes

\begin{tabular}{|l|c|c|c|c|}
\hline & $\begin{array}{c}\text { Ter ensino } \\
\text { superior }\end{array}$ & $\begin{array}{c}\text { Declarar-se } \\
\text { branca }\end{array}$ & $\begin{array}{c}\text { Pertencer a } \\
\text { estrato alto }\end{array}$ & $\begin{array}{c}\text { Ano adicional } \\
\text { de idade }\end{array}$ \\
\hline $\begin{array}{l}\text { Acesso } \\
\text { Probabilidade de ter Página (\%) }\end{array}$ & +10.4 & +12.7 & +20 & - \\
\hline $\begin{array}{l}\text { Uso contínuo } \\
\begin{array}{l}\text { Probabilidade de manter Página } \\
(\%)\end{array}\end{array}$ & +13.2 & +10.9 & +22.7 & -0.5 \\
\hline $\begin{array}{l}\text { Intensidade } \\
\text { Qtd. de postagens na Página (\%) }\end{array}$ & +59 & +37 & - & $-1,1$ \\
\hline $\begin{array}{l}\text { Foco } \\
\text { Porcentagem de postagem de } \\
\text { campanha na Página (pp) }\end{array}$ & - & - & +5.3 & - \\
\hline $\begin{array}{l}\text { Probabilidade de } \\
\text { impulsionamento (\%) }\end{array}$ & +13.8 & +8.6 & +16.1 & -0.5 \\
\hline
\end{tabular}

Fonte: Elaboração própria com base em dados do TSE e no monitoramento de Páginas e Perfis de candidatas no Facebook.

A Tabela 2 revela que ter ensino superior completo, ser branca e pertencer a um estrato sócio-ocupacional alto se correlacionaram significativamente ao acesso e ao uso contínuo da ferramenta Página. Respectivamente, candidatas desses grupos possuem probabilidade $10,4 \%, 12,7 \%$ e $20 \%$ maiores de terem uma Página. No caso da manutenção da Página pelas sete semanas, essas variáveis estão ligadas a um aumento de 13,2\%, $10,9 \%$ e $22,7 \%$ na probabilidade de a candidata fazer uso contínuo da ferramenta.

Candidatas com ensino superior e candidatas brancas ainda mostraram uma quantidade total de postagens na Página 59\% e 37\% maiores, respectivamente, que candidatas identificadas como negras, pardas, indígenas ou amarelas. $O$ estrato sócioocupacional alto ainda se correlacionou de maneira positiva com o foco das postagens na própria campanha. Candidatas que pertenciam a um estrato alto tiveram um percentual de postagens de campanha 5,3 pontos percentuais acima das demais em média. A idade teve correlação negativa sobre a probabilidade de continuidade do uso, na quantidade de postagens (intensidade) e na probabilidade de uso do impulsionamento $(-0,5 \%,-1,1 \%$ e $0,5 \%$ para cada ano adicional, respectivamente).

O impulsionamento se mostrou uma funcionalidade muito correlacionada com as variáveis explicativas. Todas elas apresentaram correlação estatisticamente significante. A probabilidade de a candidata ter usado impulsionamento de postagens aumenta $13,8 \%$ para quem tem ensino superior; $8,6 \%$ para candidatas brancas e $16,1 \%$ para candidatas que pertencem a um estrato sócio-ocupacional alto, e cai 0,5\% para cada ano adicional na idade das candidatas.

Desse modo, podemos concluir que, de maneira geral, as hipóteses de $\mathrm{H} 1$ a $\mathrm{H} 4$ foram confirmadas para as análises das Páginas e para o impulsionamento. Apenas uma variável dependente (foco) apresentou pouca correlação significativa com as variáveis analisadas. A variável idade não teve uma correlação significante com mais de uma das variáveis dependentes (acesso e foco), mas teve resultados consistentes nas demais (uso 
contínuo, intensidade e impulsionamento). Quando a correlação se mostrou estatisticamente significante, o sinal encontrado seguiu a mesma direção proposta pela hipótese para as quatro variáveis analisadas (ou seja, positivo quando a hipótese previa uma correlação positiva e negativo quando a hipótese previa uma correlação negativa). No caso dos Perfis, como já salientado acima, os resultados não confirmaram as hipóteses levantadas, o que sugere que o uso dessa ferramenta não apresenta correlações claras com as variáveis analisadas.

\section{Considerações finais}

Este artigo traz novas evidências para o debate sobre o uso das redes sociais para fins eleitorais em geral, mas particularmente em campanhas de mulheres com diferentes perfis socioeconômicos. Questionamos se as desigualdades entre as mulheres presentes na sociedade, em especial as diferenças de raça/cor, nível educacional, estrato sócioocupacional e idade, se manifestam também no uso eleitoral de Página ou Perfil do Facebook pelas candidatas ao cargo de deputado federal pelo estado de São Paulo nas eleições de 2018. Os resultados das análises indicam que sim. Grupos diferentes de candidatas dentro dessas variáveis socioeconômicas se correlacionam com diferenças no uso dessa rede social.

Tomando como base que, entre as 465 candidatas que disputaram o cargo por São Paulo, 64\% (299) tiveram Página e 80\% (374) tiveram Perfil em ao menos uma semana de campanha, os dados revelam que um número bastante considerável de candidatas teve acesso ao Facebook. Ainda assim, ter ensino superior completo, ser branca, ser de um estrato sócio-ocupacional mais alto e ter menos idade são fatores que influenciam postivamente no acesso e/ou no uso contínuo, especialmente no que concerne à Página e ao impulsionamento, que consideramos, respectivamente, uma ferramenta e uma funcionalidade de caráter mais profissional. Quando analisamos pela perspectiva não apenas do acesso, mas também das habilidades de uso, a desigualdade se manifesta de maneira mais intensa, o que corrobora a literatura analisada, em especial o estudo de Hargittai e Hsieh (2013), que mostra que as habilidades no uso da internet podem ser influenciadas pelos aparatos sociais de que a pessoa dispõe, como o nível educacional e financeiro, indicando que há uma relação entre o status socioeconômico e a posse de recursos digitais.

Os presentes achados seguem as evidências levantadas por estudos realizados em diferentes locais e contextos. A idade das candidatas - variável que tem sido colocada como uma das mais relevantes nas análises sobre redes sociais e política - apresentou um impacto significante na direção esperada: impacta negativamente a continuidade e a intensidade no uso da Página, ou seja, quanto maior a idade, menos contínuo é o seu uso e menor a sua intensidade. A correlação da forma como as candidatas utilizaram as 
ferramentas com a raça/cor, o grau de instrução e o estrato sócio-ocupacional pode indicar que a trajetória de vida das candidatas influencia no acesso a habilidades necessárias para fazerem um uso mais intenso das redes sociais durante o período eleitoral, o que demonstra uma reprodução de desigualdades.

Resultados muito semelhantes foram encontrados para o uso do impulsionamento, o que era esperado, já que este está condicionado à adesão à ferramenta Página e ao pagamento de uma quantia em dinheiro pela funcionalidade.

Um ponto relevante foi a ausência quase total de correlações das variáveis explicativas com a variável de foco de uso das ferramentas, isto é, a porcentagem de publicações correspondentes à divulgação da própria campanha. Uma possível explicação para esse fato é que, uma vez ultrapassado o obstáculo de acesso às ferramentas, o foco passa a ser praticamente igual entre as candidatas, ou seja, elas aproveitam a ferramenta de maneira similar para fins de campanha.

Com relação ao Perfil, encontramos bem menos correlações significantes do que em relação à Página. Apenas as variáveis estrato sócio-ocupacional alto e idade mostraram-se relevantes para explicar diferenças no uso dessa ferramenta (mesmo assim, com coeficientes muito próximos de zero). No caso particular do estrato sócio-ocupacional, é possível que essa variável esteja capturando o efeito das demais, dado que, no contexto socioeconômico brasileiro, elas se correlacionam intensamente. Esse resultado também indica que, mesmo que a ferramenta Perfil seja mais disseminada, pode ainda haver desigualdades no seu modo de utilização, pelo menos durante a campanha eleitoral, que precisam ser estudadas mais profundamente.

Portanto, as ferramentas online disponíveis na internet não parecem ser fruídas de maneira tão "democrática" como pressupunham as teorias mais otimistas. Os dados apontam que, sem um planejamento especial envolvendo estrutura e aprendizado de habilidades específicas, realizar uma campanha eleitoral nas redes sociais pode não ser tão simples e barato como se poderia pensar a princípio. Em vez de equalizar as capacidades de campanha em um ambiente de desigualdades extremas, as ferramentas de redes sociais tendem a reproduzir essas desigualdades se não forem garantidas condições mais equilibradas de estruturação das campanhas e de aprendizado das habilidades necessárias para operá-las.

Essa correlação pode nos indicar que não basta apenas ter o mesmo acesso às ferramentas se a capacidade de usufruir de seus benefícios for desigual. Um uso intensivo dessas redes - algo que supostamente será cada vez mais comum em uma campanha eleitoral - deve demandar uma capacidade de domínio da ferramenta, que pode depender da situação da candidata antes da campanha, especialmente seu grau de instrução e seu estrato sócio-ocupacional. A isso, há de se somar, seja para mitigar as desigualdades, seja para aprofundá-las, a capacidade de angariar recursos partidários de caráter financeiro, para viabilizar, por exemplo, o impulsionamento de conteúdo e o pagamento de recursos 
organizacionais, além de pessoal especialmente designado para alimentar conteúdos e com conhecimento para tanto.

Os dados indicam a necessidade de se adotar certa cautela, pois parecem afastar uma visão mais otimista em relação à capacidade de democratização das campanhas eleitorais em redes sociais pela mitigação das diferenças entre o offline e o online. Pelo menos entre mulheres com perfis socioeconômicos distintos, os dados corroboram a aposta dos normalizadores, isto é, autores cujos estudos apontam que a internet apenas replica as atuais relações políticas e de poder existentes no ambiente offline e, por isso, são céticos em encarar a internet como uma ferramenta de renovação da política ou de redistribuição de poder. Poder-se-ia supor, nessa linha, que as diferenças já mapeadas na literatura entre as campanhas de homens e mulheres e de brancos e não brancos, além das barreiras que as mulheres enfrentam nas disputas político-eleitorais, seriam replicadas no uso do Facebook, em que se captam diferenças entrecruzadas de gênero e raça. A falta de habilidades de uso das redes sociais em campanha eleitoral - ou a ausência de recursos necessários para adquiri-las - pode ser apontada como uma nova barreira às mulheres no processo eleitoral, especialmente às mulheres não brancas, com grau de escolaridade e estrato sócio-ocupacional baixos, complementando a análise sobre os obstáculos à inserção de mulheres na política institucional de um ponto de vista interseccional.

O que aqui se apresentou visa contribuir para uma agenda de pesquisa mais ampla, em primeiro lugar, informada pela necessidade de olhar para as mulheres candidatas não como um bloco monolítico, mas como um grupo com diversas identidades, e, em segundo lugar, voltada ao exame do uso das redes sociais como um novo recurso de campanha eleitoral e, em especial, ao exame da forma como esse novo e importante recurso é utilizado por essas candidatas marcadamente diferentes. Essa agenda pode reunir estudos que comparem o uso dessas ferramentas entre candidatos e candidatas, a fim de verificar se há diferenças de gênero e raça nesse cenário. Pode ainda ir além. Na comparação entre ou intragrupos, abre-se a possibilidade de desenvolver trabalhos que busquem identificar outras variáveis que expliquem a melhor ou pior utilização do Facebook e a sua influência no resultado da votação - por exemplo, ser candidata à reeleição ou novata, ter algum capital político ou não ter visibilidade prévia, ter alta ou baixa receita de campanha -, bem como trabalhos que procurem replicar a metodologia aqui adotada em outros estados da federação para uma análise das diferenças regionais no uso das redes sociais.

\section{Referências bibliográficas}

Aggio, C.; ReIS, L. "Campanha eleitoral no Facebook: usos, configurações e o papel atribuído a esse site por três candidatos eleitos nas eleições municipais de 2012". Compolítica, Rio de Janeiro, vol. 2, no 3, p. 155-188, jul.-dez. 2013.

Akotirene, C. Interseccionalidade. São Paulo: Polén, 2019. 
Albuquerque, A., et al. "Redes de campanha de pré-candidatos à prefeitura do Rio de Janeiro". Em Debate, Belo Horizonte, vol. 8, n० 6, p. 8-23, ago. 2016.

ANSTEAD, N.; CHADWICK, A. Parties, election campaigning, and the Internet: toward a comparative institutional approach. In: CHADWICK, A.; HowARD, P. N. (eds.). The Routledge Handbook of Internet Politics. Londres: Routledge, p. 56-71, 2009.

Araújo, C. "Potencialidades e limites da política de cotas no Brasil". Revista Estudos Feministas, Florianópolis, vol. 9, no 1, p. 231-252, 2001.

. "Partidos políticos e gênero: mediações nas rotas de ingresso das mulheres na representação política". Revista de Sociologia e Política, vol. 24, p. 193-215, 2005.

BALlington, J. Gender equality in political party funding. In: Austin, R.; TJERNSTRÖM, M. (eds.). Funding of political parties and election campaigns. Stockholm: Idea, 2003.

BILGE, S. "Théorisations féministes de l'intersectionnalité". Diogène, vol. 225, no 1, p. 70-88, 2009.

BorBA, F. "Medindo a propaganda negativa na TV, rádio, debates, imprensa e Facebook: o caso das eleições presidenciais de 2014". Intercom - RBCC, São Paulo, vol. 42, no 1, p. 37-56, jan.-abr. 2019.

Boulianne, S. "Does internet use affect engagement? A meta-analysis of research". Political Communication, vol. 26, no 2, p. 193-211, 2009.

Braga, S; Carlomagno, M. "Eleições como de costume? Uma análise longitudinal das mudanças provocadas nas campanhas eleitorais brasileiras pelas tecnologias digitais (1998-2016)". Revista Brasileira de Ciência Política, Brasília, no 26, p. 7-62, maio-ago. 2018.

CAMPOS, L. A.; MACHADO, C. "A cor dos eleitos: determinantes da sub-representação política dos não brancos no Brasil". Revista Brasileira de Ciência Política, Brasília, no 16, p. 121-151, jan.-abr. 2015.

CARneiro, A. S. "Mulheres negras e poder: um ensaio sobre a ausência". Revista do Observatório Brasil da Igualdade de Gênero. Brasília, Secretaria Especial de Políticas para as Mulheres, 2009. Disponível em: <https://bibliotecadigital.mdh.gov.br/jspui/handle/192/643>. Acesso em: 8 jul. 2021.

. "Enegrecer o feminismo: a situação da mulher negra na América Latina a partir de uma perspectiva de gênero" (online). Portal Geledés, 2011. Disponível em: <https://www.geledes.org.br/enegrecer-o-feminismo-situacao-da-mulher-negra-na-america-latinapartir-de-uma-perspectiva-de-genero/>. Acesso em: 8 jul. 2021.

Codato, A.; LobAto, T.; CAStro, O. "'Vamos lutar, parentes!' As candidaturas indígenas nas eleições de 2014 no Brasil". Revista Brasileira de Ciências Sociais, vol. 32, no 93, 2017.

CRENSHAW, K. W. "Demarginalizing the intersection of race and sex: a black feminist critique of antidiscrimination doctrine, feminist theory and antiracist politics". University of Chicago Legal Forum, vol. 1.989, no 1, 1989.

DAvis, A. Mulheres, raça e classe. São Paulo: Boitempo, 2016.

Dimaggio, P.; Hargittai, E. "From the 'digital divide' to 'digital inequality': studying internet use as penetration increases". Princeton University Center for Arts and Cultural Policy Studies, Working Paper Series no 15, 2001. Disponível em:

<https://culturalpolicy.princeton.edu/sites/culturalpolicy/files/wp15_dimaggio_hargittai.pdf>. Acesso em: 17 dez. 2019. 
DIMAGGiO, P, et al. "Digital inequality: from unequal access to differentiated use: a literature review and agenda for research on the digital inequality", 2004. Disponível em:

<http://www.webuse.org/pdf/DiMaggioEtAl-DigitalInequality2004.pdf>. Acesso em: 20 dez. 2019.

EUfRAUZino, L. F. "Marketing político e mídias sociais: as estratégias utilizadas no Facebook e Twitter de Cássio Cunha Lima (PSDB-PB), nas eleições de 2014". Dissertação de mestrado no Programa de Pós-Graduação em Estudos da Mídia. Universidade Federal do Rio Grande do Norte (UFRN), Natal, 2015.

GoMES, R. C. A. "De 'tia-do-café' a parlamentar: a sub-representação das mulheres negras e a reforma política". Revista Sociais \& Humanas, vol. 31, nº 1, p. 49-80, 2018.

Gonçalves, L.; FerReira, A. R. "Facebook: a nova ferramenta de Campanha Eleitoral Digital". Panorama, vol. 3, no 1, jan.-dez. 2013.

Gonzales, L. "Racismo e sexismo na cultura brasileira". Revista Ciências Sociais Hoje, São Paulo, Anpocs, p. 223-244, 1984. $141,1988$.

"Por um feminismo afro-latino-americano". Isis Internacional, Santiago, vol. 9, p. 133-

GuilLÉn, M. F.; SUÁREZ, S. L. "Explaining the global digital divide: economic, political and sociological drivers of cross-national internet use". Social Forces, vol. 84, no 2, p. 681-708, 2005.

GulATI, G. J.; Williams, C. B. "Social media and campaign 2012: developments and trends for Facebook adoption". Social Science Computer Review, vol. 5, no 31, p. 577-588, 2013.

HARGITTAI, E. "Second-level digital divide: differences in people's online skills". First Monday, vol. 7, no 2, abr. 2002. Disponível em <https://firstmonday.org/ojs/index.php/fm/article/view/942/864>. Acesso em: 28 nov. 2019.

Hargittai, E.; HSIeH, Y. Digital inequality. In: Dutton W. H. (ed.). The Oxford Handbook of Internet Studies. Oxford: Oxford University Press, mar. 2013.

HerRnson, P. S.; Stokes-Brown, A. K.; Hindman, M. "Campaign politics and the digital divide: constituency characteristics, strategic considerations, and candidate internet use in state legislative elections". Political Research Quarterly, vol. 60, n 1, p. 31-42, mar. 2007.

Hill Collins, P. Intersectionality as critical social theory. Durham: Duke University Press, 2019.

Hill Collins, P.; Bilge, S. Intersectionality. Cambridge (UK): Polity, 2016.

HiRATA, H. "Gênero, classe e raça interseccionalidade e consubstancialidade das relações sociais". Tempo Social, São Paulo, no 26, vol. 1, p. 61-73, 2014.

Hooks, B. "Mulheres negras: moldando a teoria feminista". Revista Brasileira de Ciência Política, Brasília, no 16, p. 193-210, 2015.

HTun, M. "A política de cotas na América Latina". Estudos Feministas, vol. 9, no 1, p. 225-230, 2001.

HTUN, M.; JONES, M. Engendering the right to participate in decision-making: electoral quotas and women's leadership in Latin America. In: CRASke, N.; Molyneux, M. (eds.). Gender and the politics of rights and democracy in Latin America. Basingstoke: Palgrave, 2002. 
ITUASSU, A., et al. "Internet, eleições e democracia: o uso das redes sociais digitais por Marcelo Freixo na campanha de 2012 para a prefeitura do Rio de Janeiro". Compolítica, Rio de Janeiro, vol. 2, no 4, ago.-dez. 2014.

JANNUZZI, P. M. "Estratificação sócio-ocupacional para estudos de mercado e pesquisa social no Brasil". São Paulo em Perspectiva, vol. 3-4, no 17, p. 247-254, 2003.

KITTILSON, M. C.; SCHWindt-BAYER, L. A. The gendered effects of electoral institutions: political engagement and participation. Oxford: Oxford University Press, 2012.

KROOK, M. L. "Gender quotas as a global phenomenon: actors and strategies in quota adoption". European Political Science, vol. 3, p. 59-65, 2004.

Quotas for women in politics: gender and candidate selection reform worldwide. Oxford: Oxford University Press, 2009.

KROOK, M. L.; NORRIS, P. "Beyond quotas: strategies to promote gender equality in elected office". Political Studies, vol. 62, p. 2-20, 2014.

MAIA, L. R. H. "A política dos eleitores no Facebook dos candidatos: processos interacionais nas eleições presidenciais de 2014". Compolítica, Rio de Janeiro, vol. 9, no 1, 2019.

Marques, F. P. J. A; Aquino, J. A.; Miola, E. "Parlamentares, representação política e redes sociais digitais: perfis de uso do Twitter na Câmara dos Deputados". Opinião Pública, Campinas, vol. 20, no 2, p. 178-203, ago. 2014.

MASSUCHIN, M. G.; TAVARES, C. Q. "Campanha eleitoral nas redes sociais: estratégias empregadas pelos candidatos à presidência em 2014 no Facebook". Compolítica, Rio de Janeiro, vol. 5, no 2, p. 75-112, 2015.

MATLAND, R. Enhancing women political participation: legislative recruitment and electoral systems. In: KARAN, A. M. (org.). Women in Parliament: Beyond Numbers. Estocolmo: International Idea (Institute for Democracy and Electoral Assistance), 1998.

Meneguello, R., et al. Mulheres e negros na política: estudo exploratório sobre o desempenho eleitoral em quatro estados brasileiros. Campinas (SP): Unicamp/Cesop, 2012.

Miola, E.; CARvalho, F. C. "Recursos persuasivos nas campanhas no Facebook: uma proposta metodológica a partir das eleições de 2016 em Curitiba". Revista de Discentes de Ciência Política da UFSCar, vol. 5, no 2, 2017.

MURTA, F., et al. "Eleições e mídias sociais: interação e participação no Facebook durante a campanha para a Câmara dos Deputados em 2014". Compolítica, Rio de Janeiro, vol. 7, nº 1, 2017.

NorRIS, P. "Recrutamento político". Revista de Sociologia e Política, vol. 21, no 46, p. 11-32, 2013.

Norris, P.; Lovenduski, J. Political recruitment: gender, race and class in the British Parliament. London: Cambridge University Press, 1995.

PACHECO, S. "Mulheres indígenas e participação política: emergência étnica feminina em um contexto de expropriação territorial". Religación. Revista de Ciencias Sociales y Humanidades, vol. 2, no 8, p. 101-114, 2017.

PANKe, L.; Thauny, J. Características do discurso eleitoral no Facebook. In: CaStilho, A.; RochA, D.; MACEDO, R. G. (orgs.). Comunicação política na esfera pública: democracia, eleições e cidadania no Brasil. Capivari, SP: Nova Consciência, 2013. 
EQUALIZAÇÃO DA DISPUTA OU REPRODUÇÃO DE DESIGUALDADES?

Penteado, C. L. C.; Pereira, N. B.; Fiacadori, G. O Planalto em disputa no Facebook: um estudo dos perfis de Dilma Rousseff e Aécio Neves nas eleições de 2014. In: CERVI, E. U; MASSUCHIN, M. G; CARVALHO, F. C. (orgs.). Internet e eleições no Brasil. Curitiba: CPOP (grupo de pesquisa em Comunicação Política e Opinião Pública), 2016.

PINTO, A. "Reinventando o feminismo: as mulheres indígenas e suas demandas de gênero". Fazendo Gênero, vol. 9, 2010.

Ribeiro, E. A.; BORBA, J.; HANSEN, J. R. "Internet e ativismo político na América Latina e Caribe: recursos individuais e oportunidades de acesso". Civitas, Porto Alegre, vol. 19, no 1, p. 261-280, jan.-abr. 2019.

RoBINSON, L., et al. "Digital inequalities and why they matter". Information, Communication \& Society, vol. 18, no 5, p. 569-582, 2015.

Ross, K.; Fountaine, S.; ComRIE, M. "Facing up to Facebook: politicians, publics and the social media(ted) turn in New Zealand". Media, Culture \& Society, vol. 37, no 2, p. 251-269, 2014.

Rossini, P. G. C., et al. "O uso do Facebook nas eleições presidenciais brasileiras de 2014: a influência das pesquisas eleitorais nas estratégias das campanhas digitais". Fronteiras - Estudos Midiáticos, vol. 18, no 2, p. 145-157, 2016.

RULE, W.; ZimermmAn, J. Electoral systems in comparative perspectives: their impact on women and minorities. London: Greenwood Press, 1994.

SACCHET, T. "Capital social, gênero e representação política no Brasil". Opinião Pública, Campinas, vol. 15, no 2, p. 306-332, 2009.

SACCHET, T.; SPECK, B. Dinheiro e sexo na política brasileira: financiamento de campanha e desempenho eleitoral em cargos legislativos. In: ALVES, J. E. D.; PINTO, C. R. J.; JORDÃo, F. (orgs.). Mulheres nas eleições de 2010. São Paulo: ABCP, p. 417-452, 2012a.

. "Financiamento eleitoral, representação política e gênero: uma análise das eleições de 2006". Opinião Pública, Campinas, vol. 18, no 1, p. 177-197, 2012b.

SANTOS, C. A participação das mulheres negras nos espaços de poder (online). Brasília (DF): Secretaria de Políticas de Promoção da Igualdade Racial - Seppir, 2010. Disponível em: $<$ https://www.gov.br/mdh/pt-br/centrais-de-conteudo/igualdade-racial/a-participacao-dasmulheres-negras-nos-espacos-de-poder>. Acesso em: 12 jul. 2020.

SANTOS, R. C. D. "Comunicação política no Facebook: a presença social dos deputados federais do Grande ABC na campanha eleitoral de 2014". Dissertação de mestrado no Programa de PósGraduação em Comunicação. Universidade Municipal de São Caetano do Sul, São Caetano do Sul, 2017.

Segato, R. L. "Uma agenda de ações afirmativas para as mulheres indígenas do Brasil". Série Antropologia, no 326, Departamento de Antropologia, Universidade de Brasília, 2003. Disponível em: <http://www.dan.unb.br/images/doc/Serie326empdf.pdf>. Acesso em: 12 jul. 2020.

SHVEDova, N. Obstacles to women's participation in parliament. In: Ballington, J.; KARAM, A. (eds.). Women in Parliament: Beyond Numbers. Stockholm: International Institute for Democracy and Electoral Assistance, p. 33-50, 2005.

Silva, E. F.; SilvA, A. A. F. S. "Marketing político no Facebook: a campanha eleitoral do prefeito eleito de Taubaté em 2012". ECCOM, vol. 6, no 11, p. 23-44, jan.-jun. 2015. 
SouzA, C. C. C. R. M. "Internet e comunicação política: uma análise da campanha online dos principais candidatos ao executivo de Macaé-RJ nas eleições de 2012". Programa de Pós-graduação em Sociologia Política: Dissertação de mestrado. Universidade Estadual do Norte Fluminense Darcy Ribeiro, 2014.

SouZA, I. J.; MARQUES, F. P. J. Campanha negativa nas eleições de 2014: uma abordagem empírica sobre como os candidatos à presidência utilizaram o Facebook. In: CERVI, E. U.; MASSUCHIN, M. G. ; CARVALHO, F. C (orgs.). Internet e eleições no Brasil. Curitiba: CPOP (grupo de pesquisa em Comunicação Política e Opinião Pública), 2016.

SouzA, P.; CEMIN, B. Mulheres indígenas em Porto Velho-RO: gênero, migração e participação política. In: SACCHI, A.; GrAmkow, M. M. (orgs.). Gênero e povos indígenas: coletânea de textos produzidos para o "Fazendo Gênero 9" e para a "27a Reunião Brasileira de Antropologia". Rio de Janeiro, Brasília: Museu do Índio/GIZ/Funai, p. 172-183, 2012.

SPECK, B. W.; MANCUSO, W. P. "A study on the impact of campaign finance, political capital and gender on electoral performance". Brazilian Political Science Review, vol. 8, nº1, p. 34-57, 2014.

Stiakakis, E.; Kariotellis, P.; Vlachopoulou, M. From the digital divide to digital inequality: a secondary research in the European Union. In: Sideridis, A. B.; PATRIKAKIS, C. Z. (eds.). Next generation society: technological and legal issues. e-Democracy 2009. Lecture notes of the Institute for Computer Sciences, Social Informatics and Telecommunications Engineering, vol. 26. Springer, Berlin, Heidelberg, p. 43-54, 2009.

VÁrallyai, L.; Herdon, M.; Botos, S. "Statistical analyses of digital divide factors". Procedia Economics and Finance, vol. 19, p. 364-372, 2015.

WooldRIDGE, J. M. Introdução à econometria: uma abordagem moderna. 4a ed. São Paulo: Cengage Learning, 2013.

Zillien, N.; HARgittai, E. "Digital Distinction: Status-Specific Types of Internet Usage". Social Science Quarterly, vol. 90, no 2, p. 274-91, 2009.

\section{Abstract}

Equalization of disputes or reproduction of inequalities? The use of Facebook by female candidates for federal deputy from Sao Paulo in 2018

This article examines whether the use of Facebook tools in election campaigns mitigates or reproduces structural socioeconomic inequalities that candidates experience in society. We monitor the use of Facebook during the 2018 election campaign to specifically understand whether and how this social media was used by candidates for the post of federal deputy for São Paulo. From a database with more than 55 thousand posts from 465 candidates, we incorporate an intersectional look at the multiple identities of these women and correlate their social markers (socio-occupational stratum, educational level, age and race/color) with the use of Facebook during the election campaign. The results of the quantitative analyzes show that, instead of equalizing pre-existing socioeconomic inequalities, this social media ended up reproducing them throughout the campaign.
\end{abstract}

Keywords: election campaigns; Facebook; internet; women in politics; inequalities

\title{
Resumen
}

¿Igualación de disputas o reproducción de desigualdades? El uso de Facebook por las candidatas de São Paulo a la Cámara Federal en 2018

Este artículo examina si el uso de herramientas de Facebook en campañas electorales mitiga o reproduce las desigualdades socioeconómicas estructurales que los candidatos experimentan en la sociedad. Supervisamos el uso de Facebook durante la campaña electoral de 2018 para comprender 
específicamente si las candidatas para el puesto de diputado federal de São Paulo utilizaron esta red social y cómo. Desde una base de datos con más de 55 mil publicaciones de 465 candidatas, incorporamos una mirada interseccional a las múltiples identidades de estas mujeres y correlacionamos sus marcadores sociales (estrato socio-ocupacional, nivel educativo, edad y raza / color) con el uso de Facebook durante la campaña electoral. Los resultados de los análisis cuantitativos muestran que, en lugar de igualar las desigualdades socioeconómicas preexistentes, esta red social terminó reproduciéndolas durante toda la campaña.

Palabras clave: campañas electorales; Facebook; internet; mujeres en la política; desigualdades

\section{Résumé}

Em francês: Egalisation des élections ou reproduction des inégalités? Utilisation de Facebook par les candidates de São Paulo à la Chambre fédérale en 2018

Cet article examine si l'utilisation des outils Facebook dans les campagnes électorales atténue ou reproduit les inégalités socio-économiques structurelles que connaissent les candidats dans la société. Nous surveillons l'utilisation de Facebook pendant la campagne électorale de 2018 pour comprendre spécifiquement si et comment ce réseau social a été utilisé par les candidats au poste de député fédéral de São Paulo. À partir d'une base de données avec plus de 55000 postes de 465 candidats, nous incorporons un regard intersectionnel sur les identités multiples de ces femmes et corrélons leurs marqueurs sociaux (strate socio-professionnelle, niveau d'éducation, âge et race/couleur) avec I'utilisation du Facebook pendant la campagne électorale. Les résultats des analyses quantitatives montrent qu'au lieu d'égaliser les inégalités socio-économiques préexistantes, ce réseau social a fini par les reproduire tout au long de la campagne.

Mots-clés: campagnes électorales; Facebook; Internet; femmes en politique; inégalités

Artigo submetido à publicação em 14 de janeiro de 2020 . Versão final aprovada em 1 de julho de 2021.

Opinião Pública adota a licença Creative Commons CC-BY.

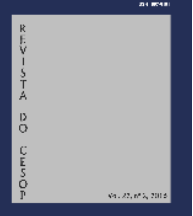

